\title{
Unsteady thermocline degradation in a fluid-saturated, porous medium
}

\author{
DOUGLAS W. STAMPS and JOHN A. CLARK \\ Department of Mechanical Engineering and Applied Mechanics, University of Michigan \\ Ann Arbor, MI 48109, U.S.A.
}

\begin{abstract}
A numerical model is developed to describe unsteady, three-dimensional, natural convective flows in a fluid-saturated, porous medium having a rectangular volume with impervious walls and finite heat transfer at the boundaries. The model is used to predict the transient decay of a thermocline in a packed bed during a period of stagnation in which there is zero net flow and no energy input into the bed. The computed results compare favorably with experimental data from a packed bed consisting of air and natural stone of mixed sizes and irregular shapes. The results show an upward shift in the position of maximum temperature along the vertical centerline of the bed and confirm the important influence of internal convection on the process. The results also demonstrate that a purely diffusive model would be incapable of a reliable predication. Further, the recognition of finite heat transfer rates at the boundaries is shown to be a significant factor in improving the predictive capability of the model.
\end{abstract}

\section{INTRODUCTION}

AN IMPORTANT example of a fluid-saturated, porous medium is a solar thermal storage device which consists of a container filled with a bed of a particulate solid, usually rock, and saturated with air. By passing heated air from a solar collector during the day through an initially cold storage device, energy is transferred from the fluid to the bed. In this process, known as charging, the inlet fluid temperature to the bed normally increases from morning to around solar noon and then decreases through the afternoon until energy is no longer capablc of bcing added to the storage device. This process creates an inherent vertical, nonlinear temperature distribution within the bed called a thermocline. The stored energy may then be subsequently reclaimed by a reverse flow process, called recovery or discharging, by passing fluid at a lower temperature through the hotter storage device. There is normally a period between the charging and discharging processes, called the hold mode, when there is no net flow through the bed. During this period, the thermocline established by the charging process degrades owing to diffusion and heat loss through the container walls. Because of the time-varying inlet temperature, the thermocline within the bed has a maximum displaced below the inlet plane at the end of the charging process, thus creating a potentially unstable region in the upper portions of the bed. It can therefore be expected that the degradation of the thermocline will also be assisted by natural convection of fluid in the bed.

The purpose of this paper is to present a numerical model describing the transient decay of a thermocline in a porous medium (for which a solar thermal storage device is a current example) and to determine the motion and temperature of the fluid within the bed. Numerical predictions of the thermocline degradation are compared with an experimental transient tem- perature profile including the effects of heat transfer between the bed and its external environment.

Of the three normal modes of operation for a packed bed used as a solar thermal storage devicecharging, hold and recovery (or discharging)--much numerical and experimental work has been done to describe the charging and recovery modes. Clark and Arpaci [1] outlined an analytical method for describing the charging mode in which the temperature of the inlet fluid varies with time. Clark et al. [2] developed a computer program named ROCKBED based on a one-dimensional model which determines the dynamic response of a rockbed energy storage device in both charging and discharging modes for any arbitrary time variation in inlet fluid temperature. Beasley and Clark [3] extended the work of Clark et al. [2] to the transient two-dimensional case (axial and radial variations) and developed a computer model called PACKBED. Computed results from this program were compared with the data obtained by Van den Broek and Clark [4] from a small [8.0 cm (3.15 in.) in diameter by $24.2 \mathrm{~cm}$ (9.53 in.) in height] cylindrical laboratory bed filled with uniform spheres $[0.56 \mathrm{~cm}$ ( 0.22 in.) in diameter] and subjected to a step change in the inlet fluid temperature. Results using PACKBED were also compared [3] with the data of Jones and Hill [5]. Favorable comparisons were obtained in each case.

All of the above studies deal only with the charging and discharging modes. Very little has been done to describe the transient decay of the thermocline during the period when there is no net flow through the bed, known as the hold mode. Margolis solves for the degradation of a one-dimensional [6-8] and multidimensional [9] time-dependent thermocline in a packed-bed thermal storage tank. His work was motivated by the needs of the central receiver solar thermal power system [10]. For the circumstances examined, the axial temperature profile in the thermal 


\section{NOMENCLATURE}

$c_{n} \quad$ specific heat

$d_{\mathrm{p}} \quad$ equivalent spherical particle diameter

$g$ acceleration of gravity

$h$ convective heat transfer coefficient

$k_{\mathrm{m}}^{*} \quad$ effective thermal conductivity of the solid-fluid matrix

$\mathbf{k}$ unit vector in the positive $z$-direction

$K$ permeability

$l$ thickness of insulation

$L_{x} \quad$ length of porous medium in the $x$ direction

$I_{y} \quad$ length of porous medium in the $y$ direction

$L_{z} \quad$ length of porous medium in the $z-$ direction

$M \quad$ total number of nodes in the $y$-direction

$N$ total number of nodes in the $x$-direction

$p_{\mathrm{T}} \quad$ dynamic pressure

$P \quad$ total number of nodes in the $z$-direction

$R \quad U L \sqrt{ } / k_{\mathrm{m}}^{*}$

$R a^{*}$ Rayleigh number,

$\left[\beta\left(T_{\mathrm{m}}-T_{\mathrm{u}}\right) g K L \sqrt{\mathrm{v}} /\left(v_{\mathrm{r}} \alpha_{\mathrm{m}}\right)\right]$

$t \quad$ time

$T$ temperature

$T_{\mathrm{m}} \quad$ maximum temperature at vertical centerline

$T_{\mathrm{u}} \quad$ upper surface temperature at vertical centerline

$U \quad$ overall heat transfer coefficient
$V$ volume-averaged velocity

$x$ reference coordinate

$y$ reference coordinate

$z$ reference coordinate.

Greek symbols

$\alpha_{\mathrm{f}} \quad$ fluid thermal diffusivity, $k_{\mathrm{f}} /\left(\rho c_{\mathrm{p}}\right)_{\mathrm{f}}$

$\alpha_{\mathrm{m}} \quad k_{\mathrm{m}}^{*} /\left(\rho c_{\mathrm{p}}\right)_{\mathrm{f}}$

$\beta \quad$ coefficient of volume expansion

$\mu \quad$ dynamic viscosity

$v \quad$ kinematic viscosity

$\rho$ density

Ф vector potential

$\psi$ porosity.

Subscripts

B bottom

ep extruded polystyrene

f fluid

$\mathrm{m}$ porous medium

pw plywood

s solid

$\mathrm{T}$ top

$\mathrm{S} \quad$ vertical sides

$\mathrm{V}$ vermiculite

$\infty$ ambient.

\section{Superscripts}

dimensional quantity. storage device at the end of charging is inherently stable with the density of the fluid decreasing monotonically with height. Accordingly, Margolis properly models the thermocline degradation by a diffusional process only.

However, the physical circumstances are quite different for a thermocline in a solar thermal storage device at the end of many normal charging processes. In these cases the thermoclinc can be identified by two regions. The lower region is inherently stable with the density of the fluid decreasing uniformly with height. The upper region, however, is potentially unstable. Here the density of the fluid continuously increases with height. Thus, a higher density fluid over-rides lower density fluid and the possibility of natural convective motion exists. Beasley et al. [11] measured the decay of a thermocline in a packed bed over a $14-\mathrm{h}$ hold period (after charging) in which there was no net through flow. Their measurements were made in a $0.370-\mathrm{m}^{3}\left(13.08-\mathrm{ft}^{3}\right)$ rockbed charged by the output of a solar collector during the daylight hours. The transient decay of the thermocline was recorded by measuring the temperatures within the storage device.
Comparisons will be made later between these measurements and calculations using the model presented in this paper.

\section{MATHEMATICAL FORMULATION AND SOLUTION METHOD}

Consider a rectangular volume of a fluid-saturated, homogeneous and isotropic porous medium having impermeable boundaries with finite heat transfer. The coordinate system is shown in Fig. 1. The following assumptions are used in the development of the mathematical formulation: (1) the Boussinesq approximation is valid; (2) the fluid density is a linear function of temperature; (3) inertial effects are negligible; (4) thermal dispersion is negligible; and (5) the fluid and solid are in local thermal equilibrium. The nondimensional governing equations are the conservation of mass, momentum and energy:

$$
\nabla \cdot \mathbf{V}=0
$$




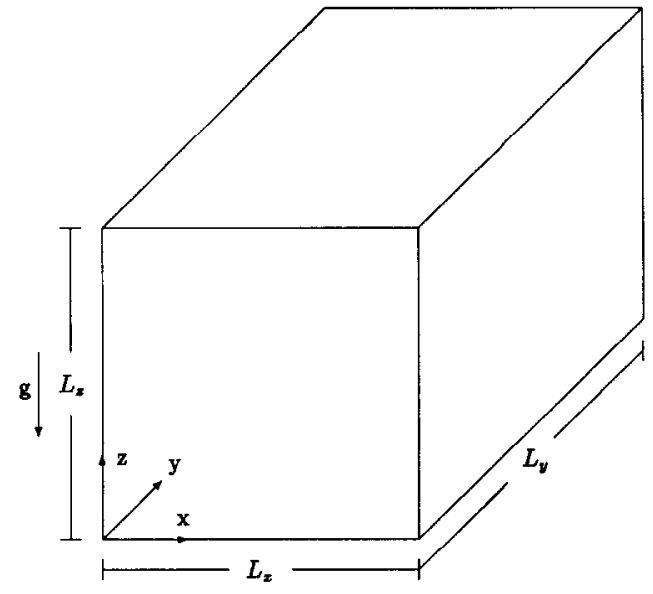

FIG. 1. Coordinate system.

$$
\begin{aligned}
& \mathbf{V}=-\nabla p_{\mathrm{T}}+R a^{*} T \mathbf{k} \\
& \frac{\partial T}{\partial t}+\mathbf{V} \cdot \nabla T=\nabla^{2} T
\end{aligned}
$$

Equations (1)-(3) are nondimensionalized by letting $\left(x^{\prime}, y^{\prime}, z^{\prime}\right)=L_{x}(x, y, z) . \mathbf{V}^{\prime}=\left(\alpha_{\mathrm{m}} / L_{\mathrm{v}}\right) \mathbf{V}, p_{\mathrm{T}}^{\prime}=\left(\alpha_{\mathrm{f}} \mu / K\right) p_{\mathrm{T}}$, $t^{\prime}=\left[\left(\rho c_{\mathrm{p}}\right)_{\mathrm{m}} L_{x}^{2} / k_{\mathrm{m}}^{*}\right] t$ and $T=\left(T^{\prime}-T_{\mathrm{u}}\right) /\left(T_{\mathrm{m}}-T_{\mathrm{u}}\right)$ where the primes denote dimensional quantities.

Horne [12] shows that by introducing a vector potential of the form

$$
\mathbf{V}=\boldsymbol{\nabla} \times \mathbf{\Phi}
$$

into the formulation, the resulting equations may be solved numerically with greater speed and accuracy than with the formulation using the primitive variables [equations (1) and (2)]. This vector potential satisfies the continuity equation identically. Hirasaki and Hellums [13] show that the potential is solenoidal since the velocity is solenoidal.

$$
\nabla \cdot \Phi=0 .
$$

Introducing equations (4) and (5) into the curl of equation (2) yields the following set of equations:

$$
\begin{gathered}
\nabla^{2} \Phi_{x}=-R a^{*} \frac{\partial T}{\partial y} \\
\nabla^{2} \Phi_{y}=R a^{*} \frac{\partial T}{\partial x} \\
\nabla^{2} \Phi_{z}=0 .
\end{gathered}
$$

For rigid boundaries, the vector potential boundary conditions are derived by Hirasaki and Hellums [13].

$$
\begin{array}{cc}
\Phi_{x}=\Phi_{y}=\frac{\partial \Phi_{z}}{\partial z}=0 & \text { at } z=0, \frac{L_{z}}{L_{x}} \\
\Phi_{x}=\frac{\partial \Phi_{y}}{\partial y}=\Phi_{z}=0 & \text { at } y=0, \frac{L_{y}}{L_{x}} \\
\frac{\partial \Phi_{x}}{\partial x}=\Phi_{y}=\Phi_{z}=0 & \text { at } x=0,1 .
\end{array}
$$

The solution to equation (8) using the boundary conditions for $\Phi_{z}$ is $\Phi_{z}=0$ everywhere.

The nondimensional thermal boundary conditions are

$$
\begin{array}{ll}
\frac{\partial T}{\partial z} \mp R\left(T-T_{x}\right)=0 & \text { at } z=0, \frac{L_{z}}{L_{x}} \\
\frac{\partial T}{\partial y} \mp R\left(T-T_{x}\right)=0 & \text { at } y=0, \frac{L_{y}}{L_{x}} \\
\frac{\partial T}{\partial x} \mp R\left(T-T_{\infty}\right)=0 & \text { at } x=0,1
\end{array}
$$

where $R$ is the thermal resistance ratio $\left(U L_{x} / k_{\mathrm{m}}^{*}\right)$. The minus sign corresponds to the coordinate at zero and the plus sign corresponds to the other coordinate value.

The parabolic part of the formulation [equation (3)] is solved using the Alternating Directions Implicit (ADI) method and the elliptic part corresponding to equations (6) and (7) is solved using the Successive Line Over-Relaxation method. These methods are described in Roache [14]. Both methods are fully implicit and are second-order accurate in space even at the boundaries. The ADI method is also secondorder accurate in time. The full second-order accuracy of the ADI method can be deteriorated by the nonlinear terms in the energy equation unless the value of the velocity terms are at the current intermediate time step. This requires an iterative process and a minimum of three iterations within each time step is performed in this study. A detailed derivation of the governing equations and description of the solution method is given by Stamps [15].

\section{RESULTS AND COMPARISON WITH DATA}

The results of the present numerical model are compared with the experimental data obtained from the packed bed of Beasley et al. [11] which consists of a porous medium of air-saturated limestone rock of irregular sizes and shapes (Fig. 2). The volume of the porous medium is $0.712 \times 0.562 \times 0.927 \mathrm{~m}$ $(28 \times 22.125 \times 36.5 \mathrm{in}$.) creating an effective storage volume of $0.370 \mathrm{~m}^{3}\left(13.08 \mathrm{ft}^{3}\right)$. The porous medium is contained by a wall with two different types of insulation combinations. On the vertical sides, 8.89 $\mathrm{cm}$ ( $3 \frac{1}{2}$ in.) of vermiculite flakes fill a hollow wall composed of $0.635 \mathrm{~cm}$ ( $\frac{1}{4}$ in.) plywood on the outside and $1.27 \mathrm{~cm}\left(\frac{1}{2}\right.$ in.) plywood on the inside. The porous medium is bounded on the top and bottom by 1.27 $\mathrm{cm}\left(\frac{1}{2}\right.$ in.) plywood and $2.54 \mathrm{~cm}$ ( 1 in.) extruded polystyrene separated by a $11.43 \mathrm{~cm}\left(4 \frac{1}{2}\right.$ in.) air spacc serving as a plenum. Table 1 gives pertinent property values of the various materials used.

A total of 12 copper-constantan thermocouples are located along the vertical centerline of the storage bed and are used to measure the fluid temperature. The locations of these thermocouples are shown in Fig. 3.

The following assumptions and approximations 


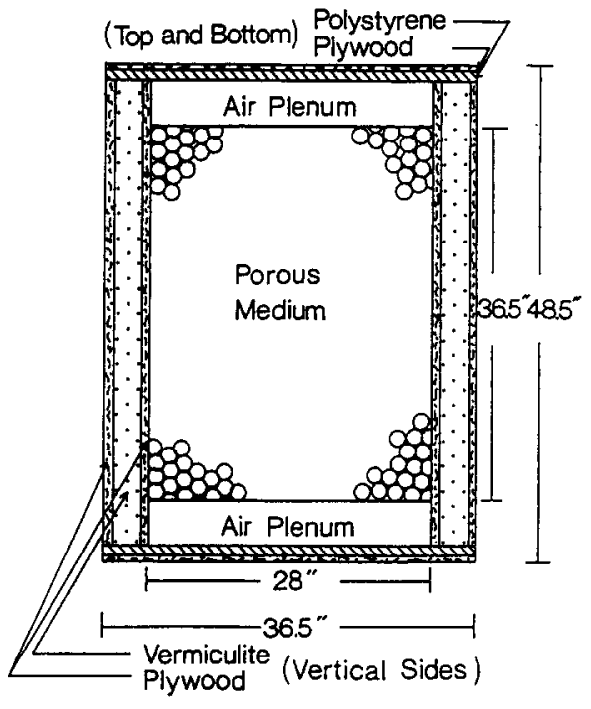

Fig. 2. Cross-section of the experimental rockbed.

apply in modeling the experimental storage device. For the boundary conditions the wall heat capacity is neglected, the ambient temperature, $T_{\infty}$, is $18.3^{\circ} \mathrm{C}$ $\left(65^{\curvearrowleft} \mathrm{F}\right)$, the thermal resistance of the plenum air space is neglected, and a typical value of $h_{\infty}=5.674 \mathrm{~W} \mathrm{~m}^{-2}$ ${ }^{\circ} \mathrm{C}^{-1}\left(1 \mathrm{Btu} \mathrm{h} \mathrm{h}^{-1} \mathrm{ft}^{-2}{ }^{\circ} \mathrm{F}^{-1}\right)$ is assumed for natural con-

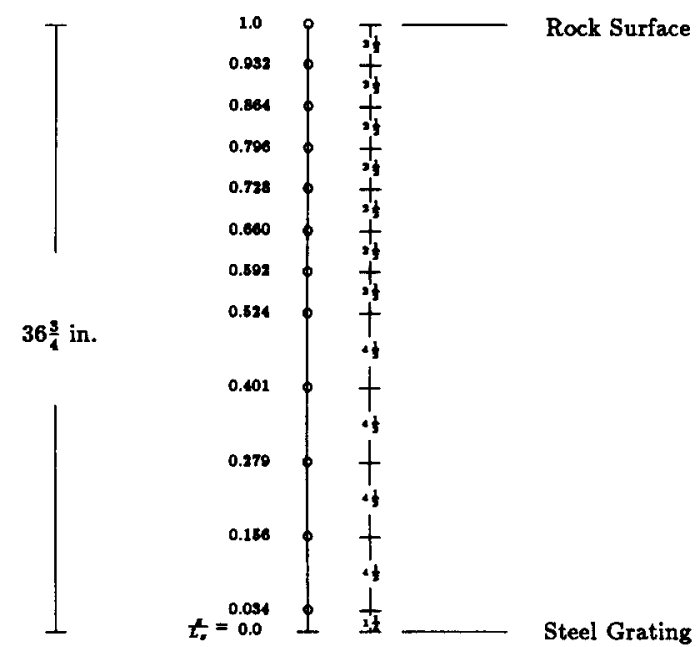

FIG. 3. Vertical spacing of thermocouples at the centerline of the experimental rockbed. vection to the air surrounding the container walls. The temperature of the concrete floor supporting the storage device is assumed to remain constant at the ambient temperature. The vertical temperature distribution everywhere in the storage device is assumed to be the same as that at the centerline. To allow the system to equilibrate after the end of the charging mode, the temperature distribution $12 \mathrm{~min}$ after the end of charging (first reading after the auto blower shutoff) is used as the initial condition. At this time, the velocity is assumed to be zero everywhere. The initial conditions for velocity and temperature for the numerical model are shown in Fig. 4. The three solid lines on the front face represent the temperature along vertical lines at the left edge, center and right edge of the cube face. The three rectangular sets of dashed lines enclosing the solid temperature lines mark the temperature range from the minimum to the maximum (left to right). The solid and dashed lines on the other vertical side have the same meanings as on the front face. Note that the two solid lines at the front right edge describe the same temperature distribution; only the perspective is different. The zero velocities are indicated by dots.

In addition to the initial conditions, the following dimensionless parameters are supplied as input to the

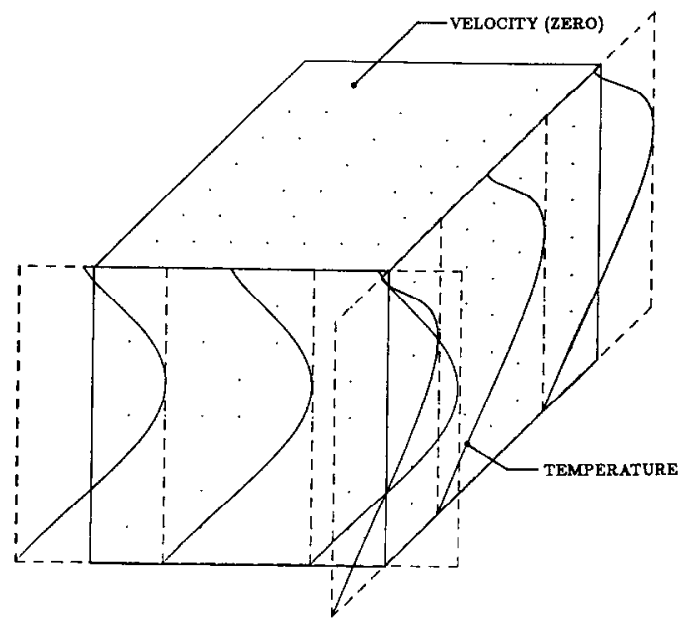

FIG. 4. Initial conditions for the model for comparison with experimental data of Beasley et al. [11]. Velocity profile and temperature distribution with grid size $N \times M \times P=$ $9 \times 9 \times 17$ at $t=0.0 \mathrm{~h}$.

Table 1. Property values. These values are at $T_{\text {avg }}=37.8^{\circ} \mathrm{C}\left(100^{\circ} \mathrm{F}\right)$ for materials used in the experiment of Beasley et al. [1:1]

\begin{tabular}{lcrcc}
\hline \multicolumn{1}{c}{ Material } & $k\left(\mathrm{~W} \mathrm{~m}^{-1}{ }^{\circ} \mathrm{C}^{-1}\right)$ & $\rho\left(\mathrm{kg} \mathrm{m}^{-3}\right)$ & $c_{\mathrm{p}}\left(\mathrm{kJ} \mathrm{kg}^{-1}{ }^{\circ} \mathrm{C}^{-1}\right)$ & $v_{\mathrm{f}}\left(\mathrm{m}^{2} \mathrm{~s}^{-1}\right)$ \\
\hline Vermiculite & 0.068 & 79.90 & 0.8355 & - \\
White pine & 0.110 & 434.50 & 2.8073 & - \\
Polystyrene & $\mathbf{0 . 0 2 7}$ & 54.94 & 1.2110 & - \\
Limestone & 2.150 & 2312.64 & 0.8108 & - \\
Air & $\mathbf{0 . 3 1 2}$ & 1.13 & 1.0081 & $1.689 \times 10^{-5}$ \\
\hline
\end{tabular}


model: Rayleigh number, thermal resistance ratio $R$, total time, ambient temperature, length ratios, grid size and time step. The Rayleigh number is defined as

$$
R a^{*} \equiv \frac{\beta\left(T_{\mathrm{m}}-T_{\mathrm{u}}\right) g K L_{x}}{v_{\mathrm{f}} \alpha_{\mathrm{m}}}
$$

The equation used to calculate the permeability, known as the Kozeny-Carman equation, is

$$
K=\frac{d_{\mathrm{p}}^{2}}{180} \frac{\psi^{3}}{(1-\psi)^{2}}
$$

where $d_{\mathrm{p}}$ is the equivalent spherical partical diameter in meters $\left(d_{\mathrm{p}}=0.034 \mathrm{~m}\right.$ or $1.34 \mathrm{in}$.) and the void fraction, $\psi$, equals 0.4 for the experimental rockbed of Beasley et al. [11]. A least-squares method is used to fit the best curve through the experimental temperature data and this curve is used to obtain the difference between the maximum temperature and the upper temperature, $T_{\mathrm{m}}-T_{\mathrm{u}}$. For this experiment, $T_{\mathrm{m}}-T_{\mathrm{u}}=$ $14.4^{\circ} \mathrm{C}\left(25.9^{\circ} \mathrm{F}\right)$. The thermal diffusivity, $\alpha_{\mathrm{m}}$, is defined as $\alpha_{\mathrm{m}}=k_{\mathrm{m}}^{*} /\left(\rho c_{\mathrm{p}}\right)_{\mathrm{f}}$ where $k_{\mathrm{m}}^{*}$ is the effective thermal conductivity of the porous medium. The model of Ofuchi and Kunii [16] is used to predict a value of $0.312 \mathrm{~W} \mathrm{~m}^{-1} \mathrm{C}^{1}\left(0.180 \mathrm{Btu} \mathrm{h}^{-1} \mathrm{ft}^{-1}{ }^{\circ} \mathrm{F}^{-1}\right)$ for the effective thermal conductivity. The coefficient of volume expansion for air is $\beta=1 / T_{\text {avg }}$ where an approximate average temperature of $37.8^{\circ} \mathrm{C}\left(100^{\circ} \mathrm{F}\right)$ is used. The Rayleigh number is calculated to be $R a^{*}=62.84$.

The thermal resistance ratio, $R$, is different for the vertical sides, $R_{\mathrm{S}}$, the top, $R_{\mathrm{T}}$, and the bottom, $R_{\mathrm{B}}$. The vertical side walls are composed of a total thickness of plywood, $l_{\mathrm{pw}}$, equal to $1.905 \mathrm{~cm}\left(\frac{3}{4} \mathrm{in}\right.$.) in series with a thickness of vermiculite flakes, $l_{v}$, equal to $8.89 \mathrm{~cm}$ ( $3 \frac{1}{2}$ in.) with an external heat transfer coefficient $\left[h_{\infty}=5.674 \mathrm{~W} \mathrm{~m}^{-2} \mathrm{C}^{-1}\left(1 \mathrm{Btu} \mathrm{h} \mathrm{h}^{-1} \mathrm{ft}^{-2}{ }^{\circ} \mathrm{F}^{-1}\right)\right]$ on the outside. Using the property values in Table 1 , the value of the overall heat transfer coefficient from the sides is found to be

$$
\begin{gathered}
U_{\mathrm{s}}=\left(\frac{l_{\mathrm{pw}}}{k_{\mathrm{pw}}}+\frac{l_{\mathrm{v}}}{k_{\mathrm{v}}}+\frac{1}{h_{\infty}}\right)^{-1} \\
=0.601 \mathrm{~W} \mathrm{~m}^{-2}{ }^{\circ} \mathrm{C}^{-1}\left(0.106 \mathrm{Btu} \mathrm{h}^{-1} \mathrm{ft}^{-2 \circ} \mathrm{F}^{-1}\right) .
\end{gathered}
$$

The value of $R_{\mathrm{S}}$ is calculated to be 1.088 from the definition $R_{\mathrm{S}} \equiv U_{\mathrm{S}} L_{\mathrm{v}} / k_{\mathrm{m}}^{*}$. The value $R_{\mathrm{T}}$ is calculated in the same manner as $R_{\mathrm{S}}$ except that the walls are composed of a thickness of plywood, $l_{\text {nu }}$, equal to 1.27 $\mathrm{cm}\left(\frac{1}{2}\right.$ in.) in series with a thickness of extruded polystyrene, $l_{\mathrm{ep}}$, equal to $2.54 \mathrm{~cm}$ ( 1 in.). A value of $R_{\mathrm{T}}=1.707$ is obtained for the top wall. The value of $R_{\mathrm{B}}$ is calculated in the same manner as $R_{\mathrm{T}}$ except there is no external heat transfer coefficient $h_{x}$. The value obtained is 1.462 .

The remaining parameters are as follows. The total time of the experiment is $13.45 \mathrm{~h}$. This corresponds to a nondimensional time, $t$, equal to 0.042 using $t=\left[\left(\rho c_{\mathrm{p}}\right)_{\mathrm{m}} L_{x}^{2} / k_{\mathrm{m}}^{*}\right] t^{\prime}$. The dimensional ambient temperature of $T_{\times}^{\prime}=18.3^{\circ} \mathrm{C}\left(65^{\circ} \mathrm{F}\right)$ corresponds to a nondimensional ambient temperature $T_{\infty}=-1.359$ from $T_{\infty}=\left(T_{\infty}^{\prime}-T_{\mathrm{u}}\right) /\left(T_{\mathrm{m}}-T_{\mathrm{u}}\right)$ where $T_{\mathrm{u}}$ is $37.9^{\circ} \mathrm{C}$ $\left(100.2^{\circ} \mathrm{F}\right)$. The length ratios, $L_{y} / L_{x}$ and $L_{z} / L_{x}$, are 1.266 and 1.650 , respectively. The grid size is $N \times M \times P=9 \times 9 \times 17$ and the time step is one-tenth the total time.

The numerical predictions of the velocity and temperature distributions after $13.45 \mathrm{~h}$ are shown in Fig. 5 . The arrows represent the velocity vectors on the cube faces and it should be noted that the volumeaveraged governing equations for porous media allow for slip on rigid walls. The length of the arrow corresponds to the magnitude of the velocity. Because the thermal resistance ratio, $R$, is large, there is enough heat loss through the vertical sides for the wall temperature to approach the ambient temperature. The air flows down the vertical sides and up the center. A comparison between the prediction of the centerline vertical temperature distribution and the experimental data after a 13.45 -h period is shown in Fig. 6 . The experimental temperature data at $t=0$ and $t=13.45$ $h$ are shown as individual points along with curves representing the best fit of the data using the linear least-squares method. The results of the numerical model are shown as a solid line obtained by drawing a smooth curve through the temperature values at each of the grid points. The peak maximum temperatures do not coincide exactly between the predictions and the experimental data at $13.45 \mathrm{~h}$. However, variations in the effective thermal conductivity can account for this difference. For air-solid combinations with ratios of thermal conductivities, $k_{\mathrm{s}} / k_{\mathrm{f}}$, close to the value of the air-limestone ratio used in the experiment, the model of Ofuchi and Kunii [16] predicts values of effective thermal conductivities within $\pm 20 \%$ of the measured value. When the value of the effective thermal conductivity in the model is varied by less than $20 \%$ the maximum peak temperatures coincide.

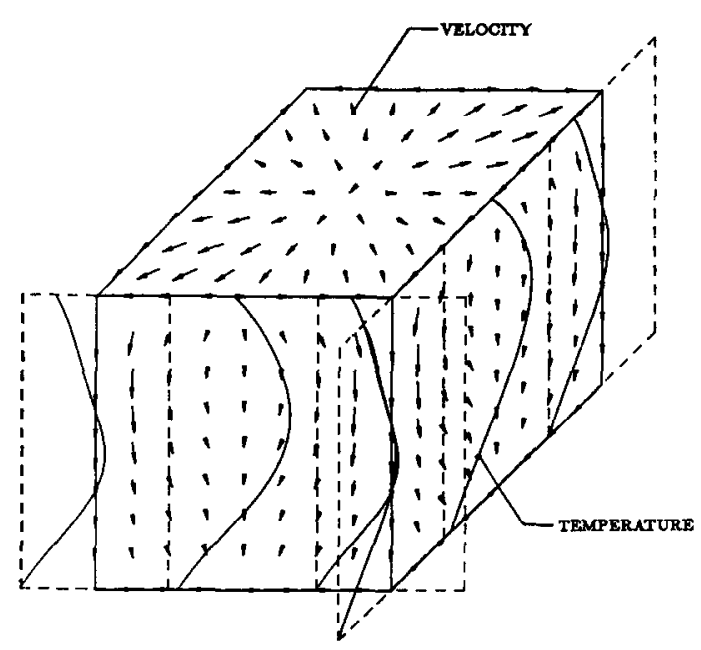

FIG. 5. Velocity profile and temperature distribution with grid size $N \times M \times P=9 \times 9 \times 17$ at $t-13.45 \mathrm{~h}$. 


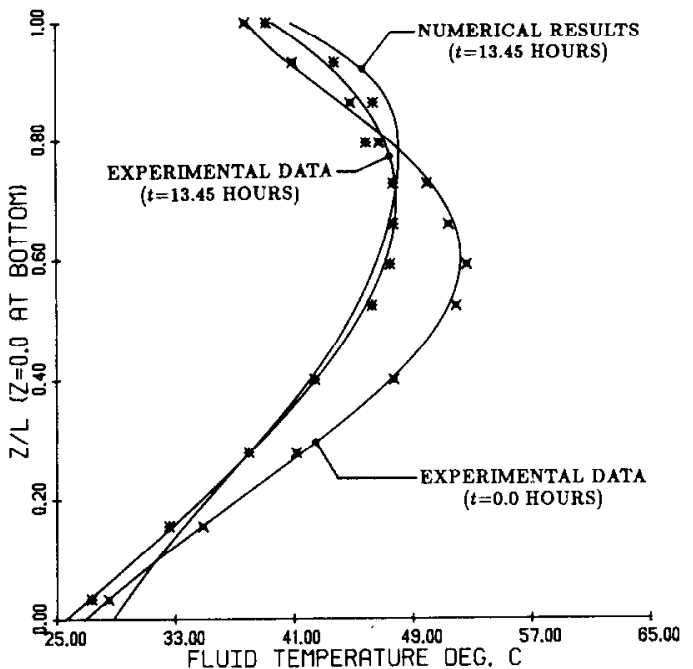

Fig. 6. A comparison between the centerline vertical temperature distribution of the model and the experimental data (*) of Beasley et al. [11] at $t=13.45 \mathrm{~h}$. Experimental data at $t=0.0 \mathrm{~h}$ are represented by $\times$.

To show the effect of natural convection in the bed, a purely diffusive case is made using the same initial conditions and parametric values and the results are shown in Fig. 7. Natural convection inside the storage device is evident by the shift upward in the peak temperature of the experimental data while the peak temperatures of the initial distribution and that for the final results of the purely diffusive case are at the same vertical position. A comparison of the numerical results in Figs. 6 and 7 with the experimental data indicates the existence of convection and the necessity of including these effects in the modeling of this process.

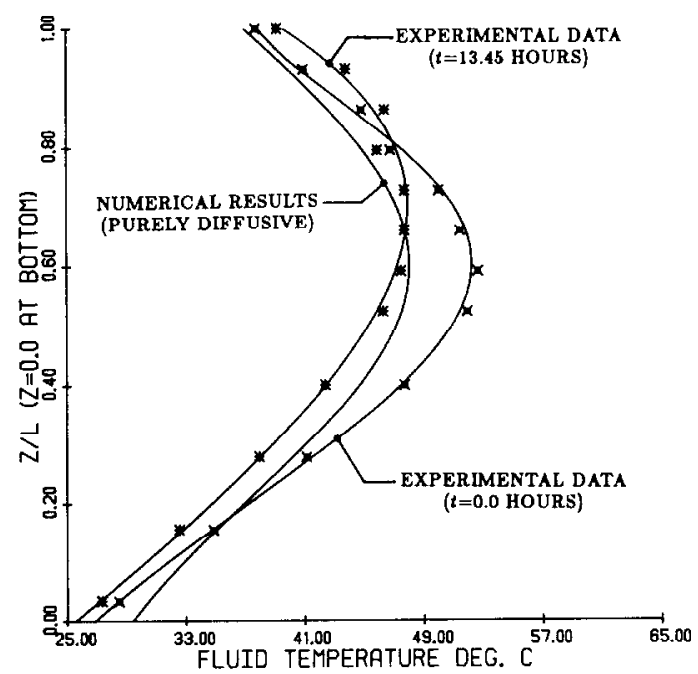

Fig. 7. A comparison between the centerline vertical temperature distribution of the model and the experimental data (*) of Beasley et al. [11] at $t=13.45 \mathrm{~h}$ for the conduction case. Experimental data at $t=0.0 \mathrm{~h}$ are represented by $\times$.

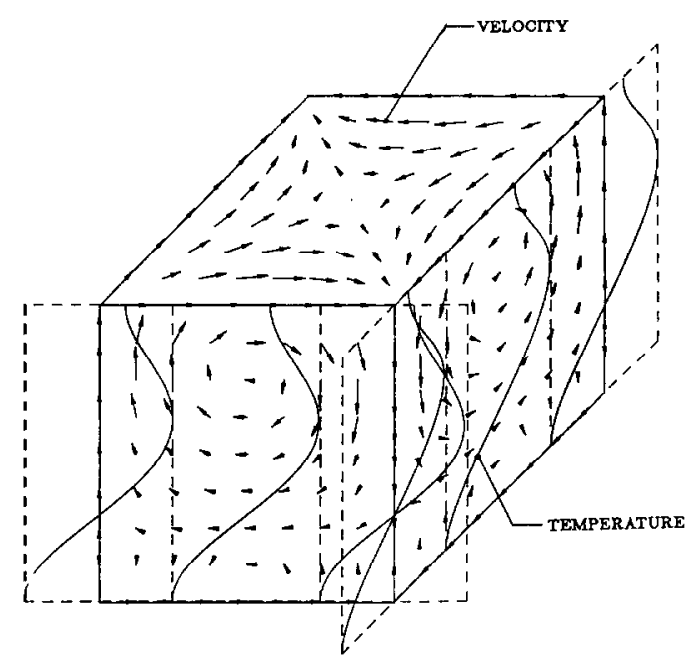

FIG. 8. Velocity profile and temperature distribution for insulated boundaries case with grid size $N \times M \times P=9 \times 9 \times 17$ at $t=13.45 \mathrm{~h}$

A condition is also studied in which all sides of the container have insulated boundaries $(R=0)$. This is done to show the effect that heat transfer at the boundaries has on the degradation of the thermocline and development of flows. Using the same initial conditions and model parameters (except that $R=0$ everywhere) as in the first case, the thermoclines and stable flow patterns at $t=13.45 \mathrm{~h}$ are shown in Fig. 8 . These are significantly different from those resulting from finite heat loss at the sides (Fig. 5). The flow is more vigorous in the upper (unstable) region as evidenced by the larger velocity vectors. A comparison also is made between the centerline vertical temperature distribution of the model and experimental data after $13.45 \mathrm{~h}$ and is shown in Fig. 9. The steep

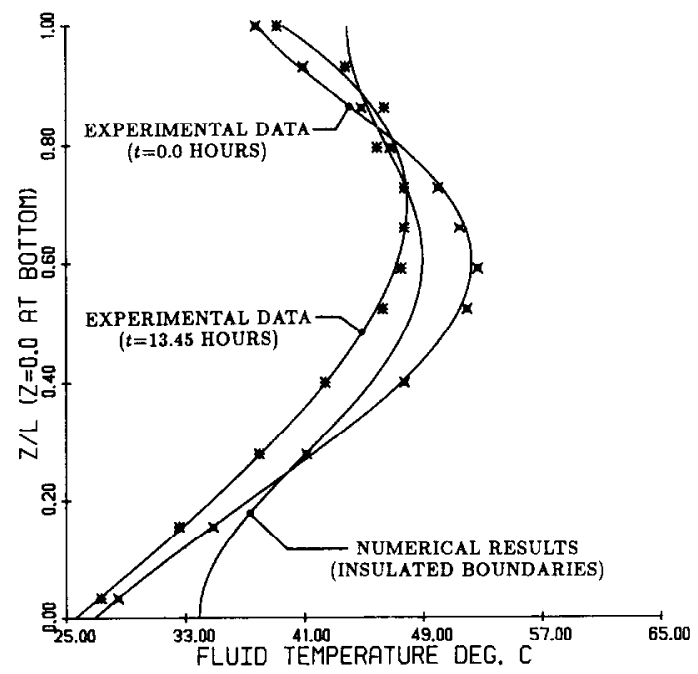

FIG. 9. A comparison between the centerline vertical temperature distribution of the model and the experimental data (*) of Beasley et al. [11] at $t=13.45 \mathrm{~h}$ with insulated boundaries. Experimental data at $t=0.0 \mathrm{~h}$ are represented by $x$. 
temperature gradients shown by the experimental data at the boundaries indicate the importance of including the effect of finite heat transfer at the boundaries. Accordingly, it appears unacceptable to model these thermal systems using perfectly insulating boundaries. The predictive ability of such models is enhanced when provision is made for finite heat transfer rates at the boundaries.

\section{CONCLUSIONS}

The transient decay of a thermocline in a packed bed for solar thermal energy storage is described for a period when there is no energy input and no net flow through the bed. Because of the time-varying inlet temperatures during the charging mode, the initial conditions for the hold mode have an unstable vertical temperature (or density) distribution that may generate a buoyancy-induced motion inside the bed. A numerical model is developed to describe unsteady. three-dimensional, natural convective flows in a rectangular, porous medium having impervious walls with finite heat transfer. Results from this model for the thermocline degradation compare favorably with experimental data from a rectangular packed bed filled with limestone rock saturated by air and surrounded with different types of insulation material. The numerical results show that fluid flows down the vertical sides and up the center of the bed creating an upward shift in the position of maximum temperature along the vertical centerline that is also observed in the experimental data. A purely diffusive model is incapable of producing these results which demonstrates the importance of natural convection inside the bed. A model of a packed bed with insulated boundaries produces a new flow that is more vigorous in the upper unstable region. However, a model that includes finite heat transfer rates at the boundaries predicts the thermocline degradation better than a model incorporating insulated boundaries.

\section{REFERENCES}

1. J. A. Clark and V. S. Arpaci, Dynamic response of a packed bed energy storage system to a time varying inlet temperature, Proc. Solar Heating and Cooling Forum, Miami Beach, FL (December 1976).

2. J. A. Clark. R. L. Nabonzy and J. H. Heetderks, ROCKBED - a computer program for thermal energy storage, Proc. Annual Meeting of the American Section of the International Solar Energy Society, Orlando, FL (June 1977).

3. D. E. Beasley and J. $\Lambda$. Clark, Transient response of a packed bed for thermal energy storage, Int. J. Heat Mass Transfer 27, 1659-1669 (1984).

4. C. Van den Broek and J. A. Clark. Heat transfer in a column packed with spheres, Heat Exchange and Solar Energy, Von Karman Institute Lecture Series (19801982).

5. D. E. Jones and J. E. Hiil, Testing of pebble-bed and phase-change thermal energy storage devices according to ASHRAE standard 94-77, NB SIR 79-1937, National Enginecring Laboratory, National Bureau of Standards (1980).

6. S. B. Margolis, Thermocline degradation in a packed hed thermal storage tank. Sandia I aboratories Report SAND 77-8032, Sandia National Laboratory, Albuquerque, NM (1977).

7. S. B. Margolis, Thermocline degradation in a packed bed thermal storage tank, J. Heat Transfer 100, 371-374 (1978).

8. S. B. Margolis, Anharmonic analysis of a time-dependent packed bed thernocline, $Q$. Jl appl. Math. 36, 97114 (1978).

9. S. B. Margolis, An analytical solution for the multidimensional degradation of a packed bed thermocline, J. Franklin Inst. 307, 39-58 (1979).

10. Control receiver solar thermal power system, Vol. 5: thermal storage subsystem, MDC G6776, McDonnell Douglas (1977).

I1. D. E. Beasley, J. A. Clark and M. J. Holstege, Observations on the decay of a thermocline in a rock bed with no net fluid fow, $J$. sol. Energy Engng 107, $50-53$ (1985).

12. R. N. Horne, Three-dimensional natural convection in a confined porous medium heated from below, $J$. Fluid Mech. 92, 75I-766 (1979).

13. G. J. Hirasaki and J. D. Hellums, A general formulation of the boundary conditions on the vector potential in three-dimensional hydrodynamics. $Q$. Jl appl. Math. 26, 331-342 (1968).

14. P. Roache, Computational Fluid Dynamics, Chap. 3. Hermosa, Albuquerque. NM (1972).

15. D. W. Stamps, Thermal instabilities in porous media. Ph.D. thesis, University of Michigan, Ann Arbor, MI (1985).

16. K. Ofuchi and D. Kunii, Heat-transfer characteristics of packed beds with stagnant fluids, Int. J. Heat Mass Transfer 8, 749-757 (1965).

\title{
DEGRADATION VARIABLE DE LA THERMOCLINE DANS UN MILIEU POREUX SATURE DE FLUIDE
}

\begin{abstract}
Résumé-Un modèle numérique est développé pour décrire la convection naturelle tridimensionnelle dans un milieu poreux saturé de fluide ayant un volume rectangulaire avec des parois imperméables et un transfert thermique fini aux frontières. Le modèle est utilisé pour prévoir la décroissance variable d'une thermocline dans un lit fixe pendant une période de stagnation où il y a un débit net nul de masse et d'énergie entrant dans le lit. Les résultats du calcul se comparent favorablement aux données expérimentales pour un lit fixe de pierres naturelles de taille et forme irrégulières et avec l'air. Les résuitats montrent une élévation de la position de la température maximale le long de la ligne verticale de symétrie du lit et ils confirment l'influence importante de la convection interne sur le mécanisme. Les résultats montrent aussi qu'un modèle purement diffusif serait incapable de prévision correcte. D'autre part, la découverte de flux de transfert thermique fini aux frontières est un facteur significatif qui montre l'aptitude du modèle à faire une bonne prévision.
\end{abstract}




\title{
INSTATIONÄRER AUSGLEICH EINES AUFGEPRÄGTEN TEMPERATURPROFILS IN
} EINEM FLUIDGESÄTTIGTEN, PORÖSEN MEDIUM

Zusammenfassung-Ein numerisches Modell zur Beschreibung instationärer dreidimensionaler natürlicher Konvektionsströmungen in einem fluidgesättigten porösen Medium von rechteckiger äußerer Form mit undurchdringlichen Wänden und endlichem Wärmeübergang an den Grenzen wurde entwickelt. Das Modell dient zur Vorhersage des instationären Ausgleichs eines aufgeprägten Temperaturprofils in einem Festbett während einer Stillstandsphase, in der das Festbett nicht durchströmt und ihm keine Energie zugeführt wird. Die Ergebnisse der Berechnungen stimmen gut mit Experimenten in einem aus Luft und Steinen unterschiedlicher Größe und Form bestehenden Festbett überein. Die Ergebnisse zeigen eine Verschiebung des Temperaturmaximums entlang der vertikalen Mittellinie des Festbetts nach oben und bestätigen den wichtigen Einfluß der inneren Konvektion auf diesen Vorgang. Ebenso zeigen die Ergebnisse, $\mathrm{da} ß$ ein reines Diffusionsmodell für zuverlässige Vorhersagen ungeeignet ist. Weiterhin wird gezeigt, $\mathrm{da} ß$ die Einbeziehung endlicher Wärmetransportraten an den Grenzen ein entscheidender Faktor zur Verbesserung der Vorhersage-Tauglichkeit bei diesem Modell ist.

\section{НЕСТАЦИОНАРНАЯ ТЕРМОКЛИННАЯ ДЕГРАДАЦИЯ В НАСЫЩЕННОЙ ЖИДКОСТЬЮ ПОРИСТОЙ СРЕДЕ}

\begin{abstract}
Аннотация - Разработана численная модель для описания трехмерных нестационарных естесівенноконвективных течений в насыщенной жидкостью пористой среде, заключенной в прямоуı ольном объемс с непроницамыми стенками и конечным теплопереносом на траницах. Модель использустся дыя расчета переходного гермоклинного затухания в плотном слое в период горможения, для которого результируюций поток равен нулю и отсутствует ввод энергии в слой. Результаты расчетов хоропо согласуются с экспериментальными данными, потученными лля плотного слоя, состоящего из воздуха и природных камней неправильной формы и различных размеров. Результаты показывают сдвиг вверх положения максимума температуры вдоль вертикальной центральной линии слоя и подтверждают важность влияния внутренней конвекции на данный пропесс. Резульгаты гакже указывают на то, что чисто диффузионная модель не дае правильноло результата. Далее показано, что учет конечных скоростей теплопереноса на гранинах являе Іся сущест венным для усовершенствования рассматриваемой модели.
\end{abstract}

